\title{
PENGARUH GAYA KEPEMIMPINAN TRANSFORMASIONAL DAN KARAKTERISTIK PEKERJAAN TERHADAP ORGANIZATIONAL CITIZENSHIP BEHAVIOR (OCB) DENGAN KOMITMEN ORGANISASIONAL SEBAGAI VARIABEL INTERVENING (Studi pada PT Indonesia Comnets Plus Regional Kalimantan)
}

\author{
Utin Devika Azzahroh a \\ *abc Magister Manajemen, Fakultas Ekonomi dan Bisnis, Universitas Tanjungpura, \\ Pontianak \\ *Email : utin.azzahroh@gmail.com \\ (Diterima November 2019; Disetujui April 2020; Dipublikasikan Oktober 2020)
}

\section{Abstrak}

Employees as human resources in an organization is the most important asset in a company which is one indicator of success to achieve organizational goals. Matters relating to the achievement of organizational goals cannot be separated from the important role of organizational citizenship behavior (OCB) contributing to the survival of the organization. In addition, organizational commitment and work characteristics of human resources can encourage the creation of organizational citizenship behavior (OCB), of course, determining the success of an organization. Other important factors such as the role of leaders who have a transformational leadership style that encourages human resources in the company to continue to be productive so as to grow organizational citizenship behavior (OCB) for all employees in the company. This research is an explanatory research (Explanatory Research) with quantitative descriptive research. This research is a survey research using a questionnaire through google docs to the employees of PT. Indonesia Comnet Plus Regional Kalimantan with 62 employees. The analytical method used in the hypothesis is path analysis.

The results of this study indicate that transformational leadership style does not significantly influence organizational commitment, job characteristics significantly influence organizational commitment, transformational leadership style and job characteristics do not significantly influence Organizational Citizenship Behavior (OCB), and organizational commitment significantly influence Organizational Citizenship Behavior (OCB) OCB) emipiris study on employees of PT Indonesia Comnet Plus Regional Kalimantan.

Keywords : Transformational Leadership Style, Job Characteristics, Organizational Commitment, Organizational Citizenship Behavior (OCB)

\section{PENDAHULUAN}

Organisasi yang merupakan wadah bagi sekelompok orang yang bekerja secara terkoordinasi untuk mencapai tujuan bersama (Jones, 2013). Untuk mencapai tujuan tersebut harus didukung oleh pegawai sebagai sumber daya manusia. Pegawai sebagai sumber daya manusia merupakan asset terpenting dalam suatu perusahaan yang merupakan salah satu indikator keberhasilan untuk mencapai tujuan organisasi, demikian halnya dengan PT Indonesia Comnets Plus sendiri yang memiliki Visi dan Misi dalam organisasi, Sesuai denganVisi PT Indonesia 
Comnets Plus yaitu menjadi penyedia solusi TIK terkemuka di Indonesia berbasis jaringan melalui pemanfaatan aset strategis. Dalam hal ini seluruh Manajemen SDM dituntut untuk memberikan perhatian yang besar kepada seluruh Pegawai untuk mewujudkan Visi PT Indonesia Comnets Plus atau disingkat ICON+. Dilain sisi pegawai seharusnya dapat memberikan kinerja yang optimal sehingga misi ICON+ yang telah ditetapkan dapat terwujud.

Pentingnya membangun OCB tidak terlepas dari komitmen sumber daya manusia terhadap organisasinya. Komitmen organisasional dari sumber daya manusia akan mendorong terciptanya OCB (Gautam, et al., 2004). Komitmen organisasional merupakan suatu sikap yang mencerminkan keinginan kuat untuk tetap berada dalam organisasi, berusaha untuk tetap sesuai dengan keinginan organisasi serta menerima nilai serta tujuan organisasi (Luthans, 2006). Komitmen organisasional ditunjukkan dengan komitmen afektif, komitmen kontinuan, dan komitmen normatif (Allen \& Meyer, 2000).

Penelitian ini diharapkan dapat mengkaji lebih dalam peran dari kepemimpinan transformasional dan karakteristik pekerjaan terhadap Organizational Citizenship Behavior (OCB) dengan komitmen organisasional sebagai variabel intervening pada PT Indonesia Comnets Plus Regional Kalimantan. Sehingga pada akhirnya dapat membentuk kinerja organisasi yang tinggi pada diri pegawai dan bertanggung jawab terhadap memberikan pelayanan yang baik dan tepat waktu, maka diperlukan berbagai faktor salah satunya yaitu peran seorang pemimpin didukung pegawai yang bisa bekerja ekstra dan mempunyai komitmen yang kuat dapat mendorong munculnya perilaku ekstra (OCB), sehingga penulis tertarik meneliti tentang "Bagaimana Pengaruh Gaya Kepemimpinan Transformasional dan Karakteristik Pekerjaan terhadap Organizational Citizenship Behavior (OCB) dengan Komitmen Organisasional Sebagai Variabel Intervening (Studi Kasus pada PT INDONESIA COMNETS PLUS Regional Kalimantan)”.

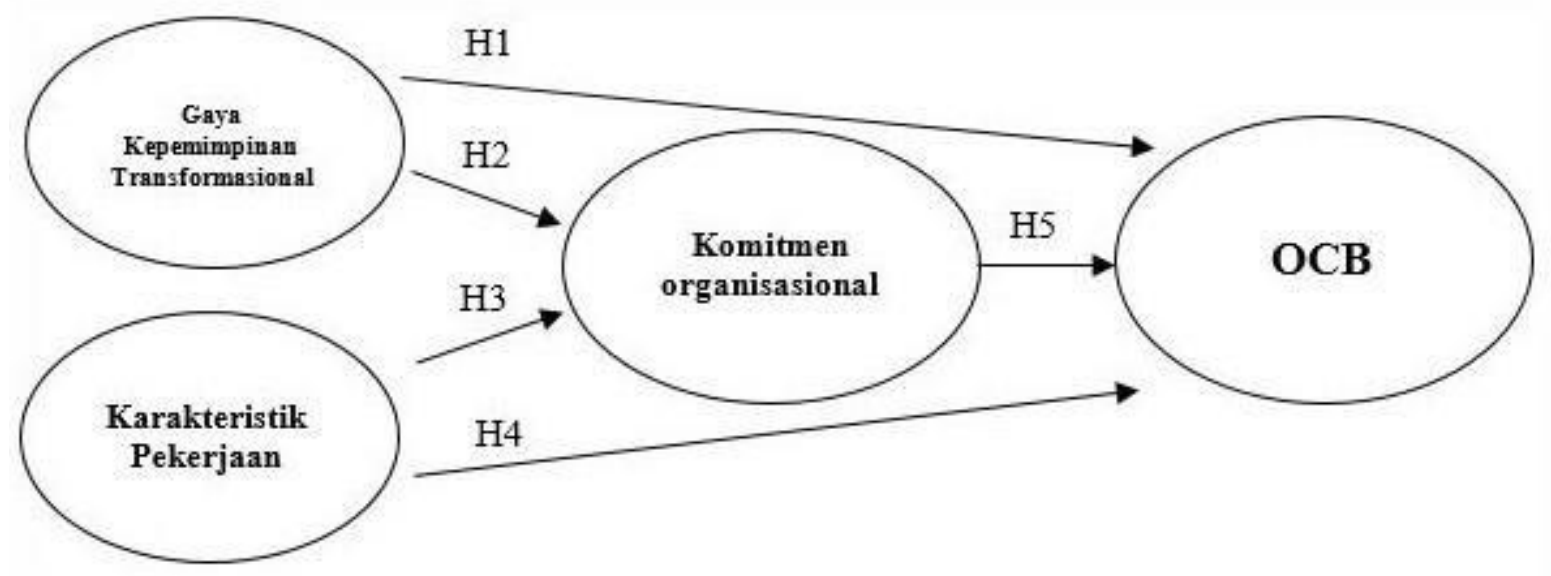

Gambar Model Penelitian 


\section{KAJIAN LITERATUR}

\section{Pengaruh Gaya Kepemimpinan Transformasional Terhadap Komitmen Organisasional}

Northouse (2013:175) menyatakan bahwa pendekatan baru yang kini popular dan diminati oleh banyak peneliti adalah pendekatan transformasional. Kepemimpinan transformasional merupakan sebuah proses dimana didalamnya orang-orang mengalami perubahan baik emosi, nilai, etika, standar maupun tujuan mereka. Downtown merupakan yang pertama kali mencetuskan istilah kepemimpinan transformasional pada tahun 1973, (Northouse, 2013). Menurut Yukl (2010) "Kepemimpinan transformasional merupakan sebuah proses membangun komitmen untuk tujuan organisasi dan pemberdayaan pengikut pada pencapaian keberhasilan. Karakteristik utama dari teori kepemimpinan transformasional adalah kemampuannya untuk menggerakkan para pengikutnya untuk mencapai melampaui komitmen harapan, (Modassir \& Singh, 2007). Mowday (2006) menyatakan komitmen organisasional adalah dimensi perilaku penting yang dapat digunakan untuk menilai kecendrungan karyawan untuk bertahan senagai anggota organisasi, identifikasi dan keterlibatan seseorang yang relatif kuat terhadap organisasi yang mempengaruhi perilaku karyawan secara tersembunyi tetapi efektif.

Penelitian yang di lakukan John dan John (2003) menjelaskan gaya kepemimpinan kepala sekolah akan membantu perkembangan atau menghambat terciptanya komitmen para guru dalam arti bahwa gaya kepemimpinan transformasional lebih efektif dalam mencapai tingkat komitmen yang lebih tinggi dan menunjukkan korelasi yang kuat dengan semua tingkat komitmen organisasi. Karyawan memiliki persepsi sendiri terhadap peran pemimpin transformasional, bagaimana perilaku pemimpin dalam memberikan pengaruh dan motivasi serta pendekatan yang dilakukan pemimpin terhadap karyawan agar karyawan dapat memiliki komitmen organisasi.Berdasarkan penjelasan diatas, maka peneliti merumuskan hipotesis pertama yakni:

H1 Gaya kepemimpinan transformasional berpengaruh signifikan terhadap komitmen organisasional.

\section{Pengaruh Karakteristik Pekerjaan Terhadap Komitmen Organisasional}

Karakteristik organisasi dan karakteristik pekerjaan adalah variabel anteseden yang diperiksa dalam penelitian ini karena relevansi mereka dengan daya tarik dan retensi karyawan, serta kontribusi positif mereka terhadap komitmen organisasi 
(Defourny et al., 2009; Rhoades dan Eisenberger, 2002). Namun, sangat sedikit penelitian yang menyelidiki kedua anteseden dalam hubungannya; dengan demikian, tidak jelas apakah mereka menghasilkan hasil yang sebanding ketika diukur secara bersamaan. Selanjutnya, meski jumlahnya relatif besar studi tentang dua variabel dalam konteks sektor swasta, beberapa studi telah memperhatikan mereka dalam konteks sektor publik, terutama dari seni dan budaya organisasi. Penelitian ini membahas kesenjangan ini dengan memeriksa efek gabungan dari kedua variabel pada komitmen organisasi karyawan dalam organisasi seni dan budaya.

Terlihat pada penelitian terdahulu menyatakan bahwa Hasil dari analisis pemodelan persamaan struktural mengungkapkan yang masuk akal daripada cocok model untuk data. Penelitian saat ini mengakui karakteristik organisasi dan pekerjaan sebagai penentu penting komitmen karyawan, terutama komponen afektifnya; yang juga ditemukan sebagai deskripsi paling akurat dari komitmen organisasi dalam organisasi seni dan budaya (Sabela, dkk 2016). Berdasarkan penjelasan diatas, maka peneliti merumuskan hipotesis ketiga yakni:

H2 Karakteristik berpengaruh signifikan terhadap komitmen organisasional

\section{Pengaruh Gaya Kepemimpinan Transformasional Terhadap Organizational Citizenship Behavior (OCB)}

Bass (1985) dalam bukunya leadership and performance di luar ekspetasi telah menyebutkan bagaimana para pemimpin transformasional menginspirasi para pengikut mencapai lebih dari biasa dengan membuat mereka menyadari potensi mereka yang sebenarnya. Kepemimpinan transformasional biasanya berteori sebagai seperangkat yang saling berhubungan perilaku yang mencakup pengaruh ideal, motivasi inspirasional, intelektual stimulasi dan pertimbangan individu (Bass, 1985). Lian dan Tui (2012) melakukan penelitian pada 347 responden yang mewakili industri seperti perusahaan jasa, manufaktur, pertambangan dan konstruksi, hasil penelitian menunjukkan bahwa gaya kepemimpinan transformasional memiliki hubungan positif yang signifikan terhadap OCB.

Penelitian ini didukung juga yang dilakukan oleh Moghimi (2013); Hutahayan, et al (2013) dan Ismaeelzadeh (2016), kepemimpinan transformasional dan perilaku warga organisasi di guru pendidikan jasmani di masyhad ada hubungan yang signifikan, penelitian subudi \& putra (2017); Suryanatha \& Ardana (2016), juga menganalisis kepemimpinan transformasional terhadap OCB, kepemimpinan tranformasional berpengaruh positif dan signifikan terhadap OCB, karena pemimpin yang mampu membaur bersama karyawan akan menimbulkan rasa suka rela dari karyawan nya, semakin baik penerapan kepemimpinan tranformasional, maka OCB pada karyawan akan meningkat. Berdasarkan penjelasan diatas, maka peneliti merumuskan hipotesis keempat yakni: 
H3 Gaya kepemimpinan tranformasional berpengaruh signifikan terhadap organizational Citizenship Behavior (OCB).

\section{Pengaruh Karakteristik Pekerjaan Terhadap Organizational Citizenship Behavior (OCB)}

Karakteristik cenderung berlanjut dalam aliran paralel. Pekerjaan karakteristik berkaitan dengan bagaimana pekerjaan dilakukan dan jangkauan dan sifat tugas yang terkait dengan pekerjaan tertentu. Karakteristik pekerjaan motivasi yang paling sering diteliti adalah otonomi, variasi tugas, makna tugas, identitas tugas dan umpan balik (Hackman \& Oldham, 1976, Hackman \& Oldham, 1980). Penelitian terbaru tampaknya menunjukkan bahwa otonomi mencerminkan sejauh mana suatu pekerjaan memungkinkan kebebasan, independensi, dan keleluasaan karyawan untuk menjadwalkan pekerjaan, membuat keputusan, dan memilih metode yang digunakan untuk melakukan tugas. Dengan demikian, otonomi mencakup tiga dimensi yang difokuskan kebebasan dalam penjadwalan kerja pengambilan keputusan, dan metode kerja (Morgeson \& Humphrey 2006).

Berbagai tugas mencerminkan sejauh mana pekerjaan membutuhkan pekerja untuk melakukan berbagai tugas di pekerjaan. Signifikansi tugas mengacu pada sejauh mana pekerjaan mempengaruhi kehidupan atau pekerjaan orang lain, baik internal atau eksternal organisasi. Pekerja dalam pekerjaan yang memiliki hasil signifikan pada kesejahteraan fisik atau psikologis orang lain cenderung mengalami kepuasan yang lebih besar dalam pekerjaan mereka. Identitas tugas mencerminkan sejauh mana pekerjaan melibatkan seluruh tubuh kerja, hasil dari yang mudah diidentifikasi. Jobs menyediakan unit layanan lengkap atau yang mengumpulkan seluruh produk selalu lebih menarik untuk dilakukan daripada pekerjaan hanya fokus pada bagian kecil dari tugas (Hackman \& Oldham, 1980; Morgeson \& Humphrey, 2006). Karakteristik pekerjaan menyebabkan keadaan psikologis positif, seperti makna dan tanggung jawab yang, pada gilirannya dapat menyebabkan perilaku kewargaan organisasi yang lebih tinggi (Banai \& Reisel, 2007). Berdasarkan penjelasan diatas, maka peneliti merumuskan hipotesis kelima yakni:

H4 Karteristik pekerjaan berpengaruh signifikan terhadap Organizational Citizenship Behavior (OCB).

\section{Pengaruh Komitmen Organisasional Terhadap Organizational Citizenship Behavior (OCB)}

Organizational Citizenship Behavior dapat timbul dari berbagai faktor dalam organisasi, diantaranya karea adanya kepuasaan kerja dan komitmen karyawan (Robbin \& Judge, 2008). Ketika karyawan merasa puas dengan apa yang ada dalam organisasi, maka karyawan akan memberikan hasil kinerja yang maksimal dan terbaik. Begitu juga dengan karyawan yang memiliki komitmen tinggi pada 
organisasi, akan melakukan apapun untuk memajukan perusahaan karena yakin dan percaya pada organisasi dimana karyawan tersebut bekerja, (Luthans, 2005).

Pada saat karyawan telah memiliki komitmen yang tinggi terhadap perusahaan, maka karyawan tersebut dengan sepenuh hati memiliki kepuasaan dalam bekerja, dan rela melakukan tindakan yang bertujuan memajukan perusahaan. Berdasarkan hal tersebut maka hipotesis yang diajukan pada penelitian ini adalah sebagai berikut:

H5 Komitmen Organisasional berpengaruh signifikan Terhadap Organizational Citizenship Behavior (OCB).

\section{METODA PENELITIAN}

Bentuk penelitian ini dilakukan untuk menguji hipotesis yang diajukan dengan menggunakan metode penelitian yang telah dirancang sesuai dengan variabel yang akan diteliti agar didapat hasil yang akurat. Bentuk penelitian yang digunakan dalam penelitian ini adalah penelitian penjelasan (Explanatory Research), dimana menurut sugiono (2012), "Explanatory Research digunakan untuk menjelaskan hubungan kausal antara variabel- variabel melalui penguji hipotesa". Jenis penelitian ini adalah deskriptif kuantitatif.

Jenis data dan pengambilan sampel yang digunakan dalam penelitian ini, jenis data yang digunakan dalam penelitian ini adalah data kualitatif (data yang berbentuk kata-kata) dan data kuantitatif (data yang berbentuk angka atau bilangan) Sedangkan sumber data yang digunakan dalam penelitian ini adalah data primer dan sekunder dengan teknik pengumpulan data adalah studi kepustakaan dan studi lapangan, selain itu variabel penelitian terdiri dari variabel bebas, variabel intervening, dan variabel terikat.

Metode analisis data yang digunakan dalam penelitian ini menurut jenjang keilmuannya statistika dibedakan menjadi dua, yaitu statistika deskriptif dan statistika inferensial. Menurut Sugiyono (2012) analisis deskriptif adalah statistik yang digunakan untuk menganalisa data dengan cara mendeskripsikan atau menggambarkan data yang telah terkumpul sebagaimana adanya tanpa bermaksud membuat kesimpulan yang berlaku untuk umum atau generalisasi. Beberapa hal yang dapat dilakukan adalah penyajian data melalui perhitungan nilai minimum, nilai maksimum, mean (pengukuran tendensi sentral) dan perhitungan penyebaran data melalui rata-rata, standar deviasi, dan perhitungan persentase. Statistika inferensia adalah teknik analisis data yang digunakan untuk menentukan sejauh mana kesamaan antara hasil yang diperoleh dari suatu sampel dengan hasil yang akan didapat pada populasi secara keseluruhan. Dalam hal ini dilakukan pengujian signifikan dari suatu analisis yang berdasarkan pada uji-t dan ujiF.

\section{HASIL PENELITIAN DAN PEMBAHASAN}




\section{Uji Validitas dan Uji Reliabilitas}

Variabel gaya kepemimpinan transformasional (X1)

Tabel Hasil Uji Validitas Angket Variabel X1

\begin{tabular}{|c|c|c|c|c|c|}
\hline Variabel & $\begin{array}{c}\text { Butir } \\
\text { Pertanyaan }\end{array}$ & $\begin{array}{l}\text { Pearson } \\
\text { Correlation }\end{array}$ & $\begin{array}{l}\text { Sig }(2- \\
\text { tailed) }\end{array}$ & $\mathbf{N}$ & Keterangan \\
\hline \multirow{22}{*}{$\begin{array}{c}\text { Gaya Kepemimpinan } \\
\text { Transformasional (X1) }\end{array}$} & 1 & 0,642 & 0 & \multirow{22}{*}{62} & \multirow{22}{*}{ Valid } \\
\hline & 2 & 0,581 & 0 & & \\
\hline & 3 & 0,678 & 0 & & \\
\hline & 4 & 0,65 & 0 & & \\
\hline & 5 & 0,471 & 0 & & \\
\hline & 6 & 0,461 & 0 & & \\
\hline & 7 & 0,367 & 0,003 & & \\
\hline & 8 & 0,605 & 0 & & \\
\hline & 9 & 0,561 & 0 & & \\
\hline & 10 & 0,55 & 0 & & \\
\hline & 11 & 0,83 & 0 & & \\
\hline & 12 & 0,72 & 0 & & \\
\hline & 13 & 0,801 & 0 & & \\
\hline & 14 & 0,472 & 0 & & \\
\hline & 15 & 0,784 & 0 & & \\
\hline & 16 & 0,803 & 0 & & \\
\hline & 17 & 0,472 & 0 & & \\
\hline & 18 & 0,784 & 0 & & \\
\hline & 19 & 0,803 & 0 & & \\
\hline & 20 & 0,472 & 0 & & \\
\hline & 21 & 0,784 & 0 & & \\
\hline & 22 & 0,803 & 0 & & \\
\hline
\end{tabular}

Berdasarkan uji validitas angket gaya kepemimpinan transformasional (X1) yang dilakukan, dari 22 item semuanya dinyatakan valid. Selanjutnya, pengujian reliabelitas angket yang dilakukan dengan Alpha Cronbach di dapat sebagai berikut:

Tabel Hasil Uji Reliabelitas X1

\section{Reliability Statistics}

\begin{tabular}{|r|rr|}
\hline \multicolumn{2}{|c|}{ Cronbach's Alpha } & N of Items \\
\hline
\end{tabular}

Kriteria penentuan apakah angket penelitian dapat dikatagorikan reliabel atau tidak, maka peneliti mengacu pada pendapat Nunali dalam Imam Ghazali (2009:46) dikatakan: "Suatu konstruk atau variabel dikatakan reliabel jika memberikan nilai Cronbach Alpha > 0,6". Berdasarkan pengujian untuk $r$, diketahui reliabelitas angket diperoleh Cronbach Alpha 0.931> 0,6. Ini menunjukan bahwa variabel yang akan diukur melalui angket penelitian adalah reliabel.

Variabel karakteristik pekerjaan

Berikut ini disajikan hasil uji validitas dan reliabelitas variabel karakteristik pekerjaan (X2): 
Tabel Hasil Uji Validitas Angket Variabel X2

\begin{tabular}{|c|c|c|c|c|c|}
\hline Variabel & $\begin{array}{c}\text { Butir } \\
\text { Pertanyaan }\end{array}$ & $\begin{array}{c}\text { Pearson } \\
\text { Correlation }\end{array}$ & $\begin{array}{c}\text { Sig (2- } \\
\text { tailed) }\end{array}$ & \multirow{2}{*}{$\mathbf{N}$} & Keterangan \\
\hline \multirow{4}{*}{$\begin{array}{c}\text { Karakteristik } \\
\text { Pekerjaan } \\
(X 2)\end{array}$} & 1 & 0,888 & 0,000 & & \\
\cline { 2 - 4 } & 2 & 0,800 & 0,000 & & \\
\cline { 2 - 4 } & 3 & 0,871 & 0,000 & & \\
\cline { 2 - 4 } & 4 & 0,935 & 0,000 & \multirow{2}{*}{62} & \multirow{2}{*}{ VALID } \\
\cline { 2 - 4 } & 6 & 0,826 & 0,000 & & \\
\cline { 2 - 4 } & 7 & 0,596 & 0,000 & & \\
\cline { 2 - 4 } & 8 & 0,817 & 0,000 & & \\
\hline
\end{tabular}

Tabel Hasil Uji Reliabelitas X2

Reliability Statistics

\begin{tabular}{|lr|c|}
\hline \multicolumn{2}{|l|}{ Cronbach's Alpha } & N of Items \\
\hline
\end{tabular}

Berdasarkan pengujian untuk $r$, diketahui reliabelitas angket diperoleh Cronbach Alpha 0,942 >0,6. Ini menunjukan bahwa variabel yang akan diukur melalui angket penelitian adalah reliabel.

Variabel Komitmen Organisasional

Tabel Hasil Uji Validitas Angket Variabel Y1

\begin{tabular}{|c|c|c|c|c|c|}
\hline Variabel & $\begin{array}{c}\text { Butir } \\
\text { Pertanyaan }\end{array}$ & $\begin{array}{c}\text { Pearson } \\
\text { Correlation }\end{array}$ & $\begin{array}{l}\text { Sig (2- } \\
\text { tailed) }\end{array}$ & $\mathbf{N}$ & Keterangan \\
\hline \multirow{11}{*}{$\begin{array}{c}\text { Komitmen } \\
\text { Organisasional } \\
\text { (Y1) }\end{array}$} & 1 & 0,775 & 0,000 & \multirow{11}{*}{62} & \multirow{11}{*}{ VALID } \\
\hline & 2 & 0,934 & 0,000 & & \\
\hline & 3 & 0,845 & 0,000 & & \\
\hline & 4 & 0,695 & 0,000 & & \\
\hline & 5 & 0,475 & 0,000 & & \\
\hline & 6 & 0,783 & 0,000 & & \\
\hline & 7 & 0,582 & 0,000 & & \\
\hline & 8 & 0,855 & 0,000 & & \\
\hline & 9 & 0,651 & 0,000 & & \\
\hline & 10 & 0,775 & 0,000 & & \\
\hline & 11 & 0,934 & 0,000 & & \\
\hline
\end{tabular}

Tabel Hasil Uji Reliabelitas Y1

Reliability Statistics

Cronbach's Alpha
$\mathrm{N}$ of Items

$$
, 921
$$

*corresponding authors e-mail : utin.azzahroh@gmail.com Online ISSN: 2721-4230 | Print ISSN: 2721-4281 DOI : http://dx.doi.org/10.26418/ejme.v8i4.43666 
PENGARUH GAYA KEPEMIMPINAN TRANSFORMASIONAL DAN KARAKTERISTIK PEKERJAAN

TERHADAP ORGANIZATIONAL CITIZENSHIP BEHAVIOR (OCB) DENGAN KOMITMEN ORGANISASIONAL SEBAGAI VARIABEL INTERVENING

(Studi pada PT Indonesia Comnets Plus Regional Kalimantan) Utin Devika Azzahroh a

Berdasarkan pengujian untuk r, diketahui reliabelitas angket diperoleh Cronbach Alpha 0,921 >0,6. Ini menunjukan bahwa variabel yang akan diukur melalui angket penelitian adalah reliabel.

\section{Variabel OCB}

Tabel Hasil Uji Validitas Angket Variabel Y2

\begin{tabular}{|c|c|c|c|c|c|}
\hline Variabel & $\begin{array}{c}\text { Butir } \\
\text { Pertanyaan }\end{array}$ & $\begin{array}{c}\text { Pearson } \\
\text { Correlation }\end{array}$ & $\begin{array}{l}\text { Sig (2- } \\
\text { tailed) }\end{array}$ & $\mathbf{N}$ & Keterangan \\
\hline \multirow{14}{*}{$\begin{array}{l}\text { OCB } \\
\text { (Y2) }\end{array}$} & 1 & 0,838 & 0,000 & \multirow{14}{*}{62} & \multirow{14}{*}{ VALID } \\
\hline & 2 & 0,679 & 0,000 & & \\
\hline & 3 & 0,57 & 0,000 & & \\
\hline & 4 & 0,72 & 0,000 & & \\
\hline & 5 & 0,758 & 0,000 & & \\
\hline & 6 & 0,867 & 0,000 & & \\
\hline & 7 & 0,724 & 0,000 & & \\
\hline & 8 & 0,604 & 0,000 & & \\
\hline & 9 & 0,797 & 0,000 & & \\
\hline & 10 & 0,769 & 0,000 & & \\
\hline & 11 & 0,792 & 0,000 & & \\
\hline & 12 & 0,606 & 0,000 & & \\
\hline & 13 & 0,539 & 0,000 & & \\
\hline & 14 & 0,347 & 0.006 & & \\
\hline
\end{tabular}

Tabel Hasil Uji Reliabelitas Y2

Reliability Statistics

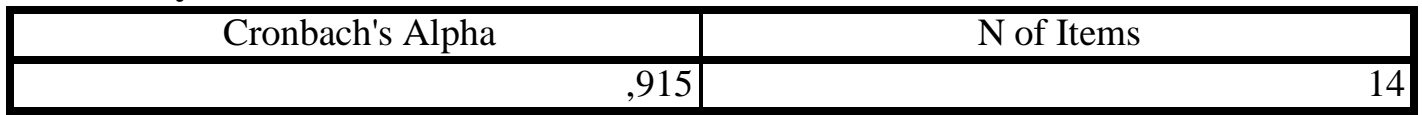

Berdasarkan pengujian untuk $r$, diketahui reliabelitas angket diperoleh Cronbach Alpha 0,915 >0,6. Ini menunjukan bahwa variabel yang akan diukur melalui angket penelitian adalah reliabel.

\section{Uji Asumsi Klasik}

Uji Normalitas

Tabel Uji Normalitas Struktur 1

Tests of Normality

\begin{tabular}{|c|c|c|c|}
\hline & \multicolumn{3}{|l|}{ Shapiro-Wilk } \\
\hline & Statistic & df & Sig. \\
\hline Unstandardized Residual_1 & 0,974 & 62 & 0,209 \\
\hline
\end{tabular}

a. Lilliefors Significance Correction 
Tabel Uji Normalitas Struktur 2

\section{Tests of Normality}

\begin{tabular}{|c|c|c|c|}
\hline & Shapiro-Wi & & \\
\hline & Statistic & $\mathrm{df}$ & Sig. \\
\hline Unstandardized Residual & 0,967 & 62 & 0,098 \\
\hline
\end{tabular}

a. Lilliefors Significance Correction

Berdasarkan tabel 4.18 dan 4.19 dapat dilihat nilai signifikan kedua residu adalah 0,209 dan 0,098 yang keduanya memiliki nilai $>0,05$. Oleh karena itu, dapat disimpulkan data pada penelitian ini berdistribusi normal.

\section{Uji Linearitas}

Tabel Uji Linearitas

\begin{tabular}{|l|c|}
\hline \multicolumn{1}{|c|}{ Variabel Penelitian } & $\begin{array}{c}\text { Signifikansi } \\
\text { Linearity }\end{array}$ \\
\hline Komitmen Organisasional (Y1) dan Gaya Kepemimpinan Transformasional (X1) & 0,008 \\
\hline Komitmen Organisasional (Y1) dan Karakteristik Pekerjaan (X2) & 0 \\
\hline OCB (Y2) dan Gaya Kepemimpinan Transformasional (X1) & 0,004 \\
\hline OCB (Y2) dan Karakteristik Pekerjaan (X2) & 0,008 \\
\hline OCB (Y2) dan Komitmen Organisasi (Y1) & 0 \\
\hline
\end{tabular}

\section{Analisis Jalur (Path Analysis)}

Hasil Persamaan Sub Struktur $1(\mathrm{Y} 1$ = b1Y1X1+b2Y1X2+ e1)

\section{Tabel Model Summary Sub Struktur 1}

Model Summary

\begin{tabular}{|r|r|r|r|r|}
\hline Model & \multicolumn{1}{|c|}{$\mathrm{R}$} & R Square & Adjusted R Square & $\begin{array}{c}\text { Std. Error of the } \\
\text { Estimate }\end{array}$ \\
\hline 1 &, $511^{\mathrm{a}}$ & 0,261 & 0,236 & 0,4121 \\
\hline
\end{tabular}

a.Predictors: (Constant), Karakteristik Pekerjaan(X2), Gaya Kep.Transformasional(X1)

b.Dependent Variable: Kom. Organisasional(Y1)

Tabel Coefficients Sub Struktur 1

\begin{tabular}{|l|c|c|c|c|}
\hline & $\begin{array}{c}\text { Unstandardized } \\
\text { Coefficients }\end{array}$ & $\begin{array}{c}\text { Standardized } \\
\text { Coefficients }\end{array}$ & & \\
\hline
\end{tabular}




\begin{tabular}{|c|c|c|c|c|c|c|}
\hline & Model & B & Std. Error & Beta & $\mathrm{t}$ & Sig. \\
\hline \multirow[t]{2}{*}{1} & (Constant) & 2,564 & 630 & & 4,067 &, 000 \\
\hline & $\begin{array}{l}\text { Gaya Kep. } \\
\text { Transformasional(X1) }\end{array}$ &,- 060 & ,119 &,- 056 &,- 504 & ,616 \\
\hline & Karakteristik Pekerjaan(X2) & ,476 & , 105 & ,506 & 4,523 & 000 \\
\hline
\end{tabular}

a. Dependent Variable: Kom. Organisasional(Y1)

Mengacu pada output hasil Regresi Model 1 (Sub Struktur 1) pada Tabel Model summary nilai R square sebesar 0.261 atau sebesar $26.1 \%$ pengaruh variabel gaya kepemimpinan transformasional, karakteristik pekerjaan, terhadap komitmen organisasional. Tabel coefficients sub struktur 1 dapat diketahui bahwa nilai signifikasi dari variabel gaya kepemimpinan transformasional sebesar $0.616>$ 0.05 sehingga dapat disimpulkan bahwa tidak berpengaruh signifikan. Variabel karakteristik pekerjaan sebesar $0.000<0.05$ dapat disimpulkan berpengaruh signifikan terhadap komitmen organisasional.

Hasil Persamaan Sub Struktur $2(Y 2=b 3 \mathrm{Y} 2 \mathrm{X} 1+\mathrm{b} 4 \mathrm{Y} 2 \mathrm{X} 2+\mathrm{b} 5 \mathrm{Y} 2 \mathrm{Y} 1+\mathrm{e} 2)$

Tabel Model Summary Sub Struktur 2

Model Summary ${ }^{\mathrm{b}}$

\begin{tabular}{|c|c|c|c|c|}
\hline Model & $\mathrm{R}$ & R Square & $\begin{array}{l}\text { Adjusted R } \\
\text { Square }\end{array}$ & $\begin{array}{l}\text { Std. Error of the } \\
\text { Estimate }\end{array}$ \\
\hline 1 &, $546^{\mathrm{a}}$ & 0,298 & 0,261 & 0,39771 \\
\hline
\end{tabular}

a. Predictors: (Constant), Kom. Organisasional(Y1), Gaya Kep.Transformasional(X1),

Karakteristik Pekerjaan(X2)

b. Dependent Variable: $\mathrm{OCB}(\mathrm{Y} 2)$

Tabel Coefficients Sub Struktur 2

\begin{tabular}{|c|c|c|c|c|c|c|}
\hline & \multirow[t]{2}{*}{ Model } & \multicolumn{2}{|c|}{$\begin{array}{l}\text { Unstandardized } \\
\text { Coefficients }\end{array}$} & \multirow{2}{*}{$\begin{array}{l}\text { Standardized } \\
\text { Coefficients } \\
\text { Beta }\end{array}$} & \multirow[t]{2}{*}{$\mathrm{t}$} & \multirow[t]{2}{*}{ Sig. } \\
\hline & & B & Std. Error & & & \\
\hline \multirow[t]{4}{*}{1} & (Constant) & 1,359 & ,688 & & 1,974 & ,053 \\
\hline & $\begin{array}{l}\text { Gaya Kep. } \\
\text { Transformasional(X1) }\end{array}$ & , 190 & , 115 & ,183 & 1,660 & , 102 \\
\hline & $\begin{array}{l}\text { Karakteristik } \\
\text { Pekerjaan(X2) }\end{array}$ &,- 006 & ,118 &,- 006 &,- 048 & ,962 \\
\hline & Kom. Organisasional(Y1) &, 520 & , 126 & ,530 & 4,139 & ,000 \\
\hline
\end{tabular}

Mengacu pada output hasil Regresi Model 2 (Sub Struktur 2) pada Tabel 4.23 Model summary nilai $\mathrm{R}$ square sebesar 0.298 atau sebesar $29.8 \%$ pengaruh variabel gaya kepemipinan transformasional, karakteristik pekerjaan, terhadap OCB. Tabel 4.24 coefficients sub struktur 2 dapat diketahui bahwa nilai signifikasi dari variabel gaya kepemimpinan transformasional sebesar $0.102>0.05$ sehingga dapat disimpulkan bahwa tidak berpengaruh signifikan terhadap OCB. Variabel karakteristik pekerjaan sebesar 0.962 > 
0.05 dapat disimpulkan tidak berpengaruh signifikan terhadap OCB. Variabel Komitmen Organisasional sebesar $0.000<0.05$ sehingga dapat disimpulkan berpengaruh signifikan terhadap OCB.

Adapun diagram jalur persamaan struktural pada penelitian ini adalah sebagai berikut :

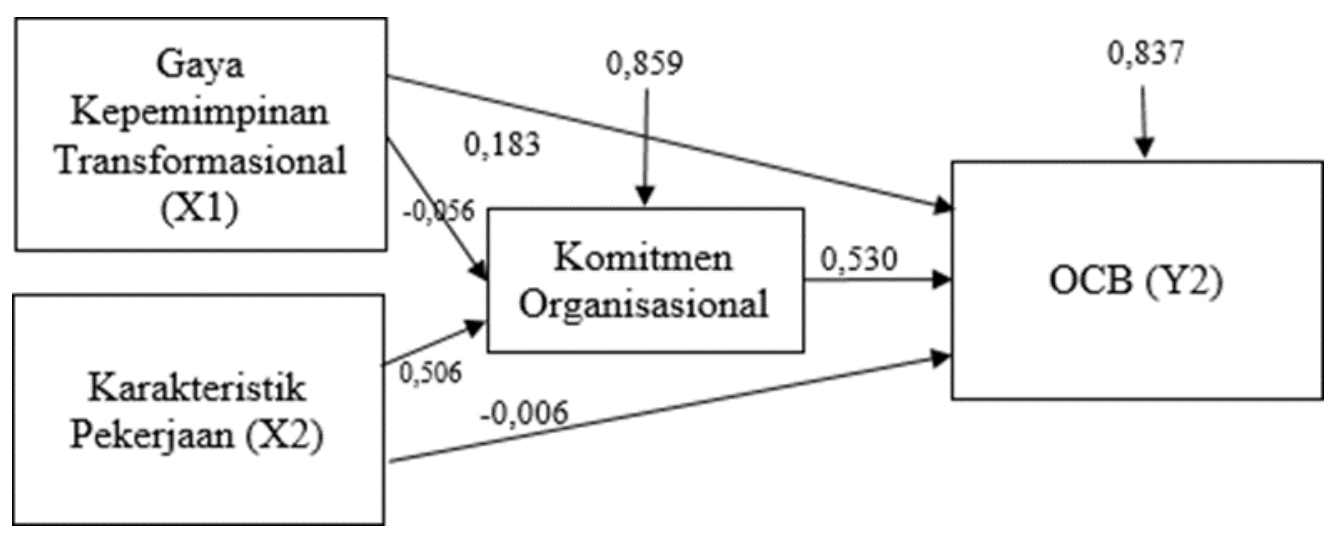

Gambar Diagram Jalur Persamaan Struktural

Total keragaman data yang dapat dijelaskan oleh model dapat diukur dengan sebagai berikut : R2m = $1-\mathrm{P} 2 \mathrm{e} 1 \mathrm{P} 2 \mathrm{e} 2 \ldots . . \mathrm{P} 2 \mathrm{ep}$ Dari kedua nilai Error tersebut selanjutnya dapat dihitung nilai koefisien determinasi total yaitu : R2m $=1$ $(0.859) 2(0.837) 2=0.485$

Dari perhitungan rumus determinasi total di atas diperoleh nilai sebesar 0,485 yang dapat disimpulkan bahwa keberagaman dapat dijelaskan oleh diagram model lintasan adalah sebesar 48,5 persen atau dengan kata lain informasi yang terkandung dalam data sebesar 48,5 persen dapat dijelaskan dengan model diagram lintasan. Sedangkan sisanya 51,5 persen dijelaskan oleh variabel lain dan error.

Langkah selanjutnya setelah analisis jalur (path analysis) adalah melakukan teori trimming. Berdasarkan teori trimming, maka jalur-jalur yang tidak signifikan dibuang, sehingga diperoleh model hasil penelitian yang didukung oleh data empirik. Nilai signifikan digunakan untuk menentukan hipotesis hubungan dari masing-masing jalur variabel. Hipotesisnya berbunyi sebagai berikut :

$\mathrm{H} 1=$ ditolak, sig $=0.616$ lebih besar dari p-value atau $\alpha=0,05$

$\mathrm{H} 2=$ diterima, sig $=0.000$ lebih kecil dari $p$-value atau $\alpha=0,05$

H3 = ditolak, sig $=0.102$ lebih besar dari p-value atau $\alpha=0,05$

$\mathrm{H} 4=$ ditolak, sig $=0.962$ lebih besar dari p-value atau $\alpha=0,05$

H5 = ditolak, sig $=0.000$ lebih besar dari p-value atau $\alpha=0,05$ 
Pengujian dilakukan dengan membandingkan angka taraf signifikansi (Sig) hasil perhitungan dengan taraf signifikansi 0,05. Berdasarkan perhitungan maka diperoleh kesimpulan :

$\mathrm{H} 1=$ ditolak artinya tidak ada hubungan linier antara gaya kepemimpinan transformasional terhadap komitmen organisasional;

$\mathrm{H} 2$ = diterima artinya ada hubungan linier antara karakteristik pekerjaan terhadap komitmen organisasional;

$\mathrm{H} 3=$ ditolak artinya tidak ada hubungan linier antara gaya kepemimpinan transformasional terhadap OCB;

$\mathrm{H} 4=$ ditolak artinya tidak ada hubungan linier antara karakteristik pekerjaan terhadap OCB;

$\mathrm{H} 5=$ ditolak artinya tidak ada hubungan linier antara komitmen organisasional terhadap OCB

Berdasarkan theory trimming, maka jalur-jalur yang non signifikan dibuang, sehingga diperoleh model yang didukung data empirik sebagai berikut :

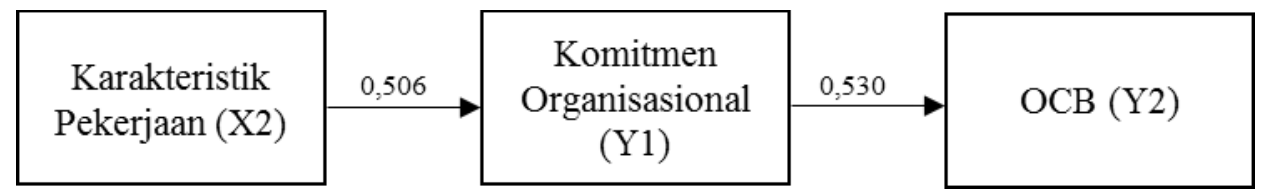

Gambar Diagram Jalur setelah dilakukan theory trimming

Hasil perhitungan pengaruh langsung antar variabel dapat kita lihat pada Tabel 4.24 berikut ini :

Tabel Pengaruh Langsung Antar Variabel

\begin{tabular}{|c|l|c|}
\hline No & \multicolumn{1}{|c|}{ Rumus } & \multicolumn{1}{|c|}{ Hasil } \\
\hline 1 & $\begin{array}{l}\text { Karakteristik Pekerjaan }(\mathrm{X} 2) \rightarrow \text { Komitmen } \\
\text { Organisasional }(\mathrm{Y} 1)\end{array}$ & $(0.506)^{2} \mathrm{X} 100 \%=25,60 \%$ \\
\hline 2 & Komitmen Organisasional $(\mathrm{Y} 1) \rightarrow$ OCB $(\mathrm{Y} 2)$ & $(0,530)^{2} \mathrm{X} 100 \%=28,09 \%$ \\
\hline
\end{tabular}

\section{PEMBAHASAN HASIL PENELITIAN}

1. Pengaruh Gaya Kepemimpinan Transformasional terhadap Komitmen Organisasional Mengacu pada output hasil regresi model 1 (sub struktur 1) pada tabel 4.21 model summary nilai $r$ square sebesar 0.261 atau sebesar $26.1 \%$ pengaruh variabel gaya kepemimpinan transformasional, karakteristik pekerjaan terhadap komitmen organisasional. Tabel 4.22 Coefficients Sub Struktur 1 dapat diketahui bahwa nilai signifikasi dari variabel gaya kepemipinan transformasional sebesar $0.616>0.05$ sehingga dapat disimpulkan bahwa tidak berpengaruh signifikan. 
2. Pengaruh Karakteristik Pekerjaan terhadap Komitmen Organisasional Mengacu pada output hasil regresi model 1 (sub struktur 1) pada tabel 4.21 model summary nilai $r$ square sebesar 0.261 atau sebesar $26.1 \%$ pengaruh variabel gaya kepemimpinan transformasional, karakteristik pekerjaan terhadap komitmen organisasional. Tabel 4.22 Coefficients Sub Struktur 1 dapat diketahui bahwa nilai signifikasi dari variabel karakteristik pekerjaan sebesar $0.000<0.05$ sehingga dapat disimpulkan bahwa berpengaruh signifikan.

3. Pengaruh Gaya Kepemimpinan Transformasional terhadap OCB Mengacu pada output hasil regresi model 2 (sub struktur 2) pada tabel 4.23 model summary nilai r square sebesar 0.298 atau sebesar $29.8 \%$ pengaruh variabel gaya kepemimpinan transformasional, karakteristik pekerjaan, komitmen organisasional terhadap OCB. Tabel 4.24 Coefficients Sub Struktur 2 dapat diketahui bahwa nilai signifikasi dari variabel gaya kepemimpinan transformasional sebesar $0.102>0.05$ sehingga dapat disimpulkan bahwa tidak berpengaruh signifikan.

4. Pengaruh Karakteristik Pekerjaan terhadap OCB Mengacu pada output hasil regresi model 2 (sub struktur 2) pada tabel 4.23 model summary nilai $r$ square sebesar 0.298 atau sebesar $29.8 \%$ pengaruh variabel gaya kepemipinan transformasional, karakteristik pekerjaan, komitmen organisasional terhadap OCB. Tabel 4.24 Coefficients Sub Struktur 2 dapat diketahui bahwa nilai signifikasi dari variabel karakteristik pekerjaan sebesar $0.962>0.05$ sehingga dapat disimpulkan bahwa tidak berpengaruh signifikan.

5. Pengaruh Komitmen Organisasional terhadap OCB Mengacu pada output hasil regresi model 2 (sub struktur 2) pada tabel 4.23 model summary nilai r square sebesar 0.298 atau sebesar $29.8 \%$ pengaruh variabel gaya kepemipinan transformasional, karakteristik pekerjaan, komitmen organisasional terhadap OCB. Tabel 4.23 Coefficients Sub Struktur 2 dapat diketahui bahwa nilai signifikasi dari variabel komitmen organisasional sebesar $0.000<0.05$ sehingga dapat disimpulkan bahwa berpengaruh signifikan. Hal tersebut membuktikan bahwa Komitmen akan meningkatkan terjadinya OCB.

\section{SIMPULAN}

Berdasarkan pengujian hipotesis dan pembahasan, maka kesimpulan dalam penelian ini yaitu gaya kepemimpinan transformasional tidak berpengaruh signifikan terhadap Komitmen Organisasional, gaya karakteristik pekerjaan berpengaruh signifikan terhadap Komitmen Organisasional, gaya kepemimpinan transformasional tidak berpengaruh signifikan terhadap OCB, karakteristik 
pekerjaan tidak berpengaruh signifikan terhadap OCB, komitmen organisasional berpengaruh signifikan terhadap OCB.

Adapun rekomendasi untuk penelitian selanjutnya yaitu diantaranya dengan melakukan komunikasi dengan pegawai dapat memahami pesan yang disampaikan oleh pemimpin dan tidak terjadi kesalahpahaman. Dengan adanya komunikasi yang jelas akan membuat pegawai memahami pekerjaan yang diberikan sehingga dapat menciptakan interaksi yang optimal dan hasil kerja yang memuaskan sehingga dapat mebubuhkan komitmen organisasional. Komunikasi yang jelas dari pemimpin juga dapat membantu karyawan memahami strategi bisnis perusahaan.

Adapun rekomendasi untuk penelitian selanjutnya yaitu dapat memperluas cakupan populasinya agar jumlah subjek penelitian lebih banyak. Serta, hasil penelitian ini bisa menjadi acuan untuk peneliti selanjutnya yang tertarik untuk meneliti faktor-faktor lain yang dapat mempengaruhi OCB, seperti dukungan organisasi, dan lain-lain. 


\section{DAFTAR PUSTAKA}

Ahdiyana, Marita. 2013. Dimensi Organizational Citizenship Behavior dalam Kinerja Organisasi.Jurnal Ilmu Administrasi.Vol. 4. No. 2. 109-184.

Allen, N.J. \& Meyer, J.P. 2000. Commitment in the workplace: Theory, research, and application California: Sage Publication.

Atmojo M, 2012, The influence of Transformasional Leadership on job Satisfaction Organizational Commitment and employee Performance, International Reseach Journal of Business Studies,Vol. 5 No.2.

Aydin, et al, 2013, The Effect of School principals'Organizational Commitment and job Satisfaction,Educational Science, Vol. 13 No. 2.

Baloch, et al, 2012, Measuring Employees Commitment as Outcome of Transformational and Transactional Leadership Styles: An Empirical Study, Abasyn Journal of Social Sciences, Vol 3 No 2.

Banai, M., Reisel, W. D\&Probst, T. M.2004. A Managerial and Personal Control Model: Predictions of Work Alienation and Organizational Commitment in Hungary. Journal of International Management. Vol. 10 No.3 375-392.

Bass. 1985. Employing Transformational Leadership to Enhance the Quality of management Development Instruction. The Journal of Management Development, Vol. 22, No. 1.

Buchanan, B. (1974). Building Organizational Commitment: The Socialization of Managers in Work Organizations. Administrative Science Quarterly, 19, 533-546.

Devece, Carlos., Marquez, Daniel-Palacios., dan Alguacil, Maria Pilar. (2015).Organizational Commitmentand Its Effects on Organizational Citizenship Behavior In a High- Unemployment Environment. Journal of Business Research.

Eisenberger, R., Armeli, S., Raxwinkel, B., Lynch D. P.; Rhoades, L. (2001), Reciprocation of Perceived Organizational Support, Journal of Applied Psychology, 86 (1): 825-836.

Esmaeili, Mahmoud Reza, Ali Pirzad, Farshid Alizadeh, 2014, Effects of Work Life Quality on Empowering and Organizational Citizenship Behavior (Case Study: Science and Research, Kohkiloye and Boyer Ahmad) Erari, Marcy Rita

Faharani, Majid., Marzieh Taghadosi and Mehdi Behboudi. 2011. An Exploration of the Relationship between Transformational 
Leadership and Organizational Commitment: The Moderating Effect of Emotional Intelligence: Case Study in Iran. International Business Research. Volume 4 Number 4, pp: 211217.

Fred Luthans, (2006), Perilaku Organisasi. Edisi Sepuluh, PT. Andi: Yogyakarta.

Gautam. Thanswor, Rolf van Dick, Ulrich Wagner, Narottam Upadhyay and Ann J.Davis. 2004. Organizational Citizenship Behavior And Organizational Commitment In Nepal,December 2004ISBN No: 1854496204

Hackman, J. R., \& Oldham, G. R. (1980). Motivation through the design of work :Test of a theory. Organizational Behavior and Human Performance, 16, 250-279.

Harwiki, Wiwiek., 2016. The Impact of Servant Leadership on Organization Culture, Organizational Commitment, Organizational Citizenship Behavior (OCB) and Employee Performance in Women Cooperatives, Elsevier Ltd., Bloomington.

Hutahayan et al., 2013, The Efect Of Transformational Leadership, Organizational Culture, Reward to Organizational Citizenship Of Employee Behavior At PT Barata Indonesia (Persero), Interdiciplinary Journal of Contemporary Research In Business, Vol. 5, No.6.

Indarti, Sri., Solimun., Fernandes, Adji Achmad Rinaldo., dan Hakim, Wardhani (2017), The effect of OCB in relationship between personality, Organizational commitment and job satisfaction on performance, Journal of Management Development, Vol. 36 issue:10, pp. 1283-1293.

Indrayanto, A., John, B., Kandy, B., dan Noermijati. 2013. "A case study of transformational leadership and para-police performance in Indonesia."Policing : An International Journal of Police Strategies and Management. Vol. 37. No. 2. pp 373-388. Emerald Insight.

Indri Djastuti dan Meyta Indraswari. (2014). Pengaruh Budaya Organisasi Dan Motivasi Terhadap Kepuasan Kerja Dalam Mempengaruhi Kinerja Karyawan Kantor Unit PT Telkom Regional IV Semarang. Tesis, Universitas Diponegoro.

John, M.C., dan John, W.T. 2003. Leadership Style, School Climate, and the Institutional Commit-ment of Teachers. Dissertation, Doctoral in Seventh-Day AdventtistSecondary Schools, in Philippines.

Jones, G. R. (2013). Understanding and Managing Organizational Behavior Sixth Edition. New Jersey: Prentice Hall.

Kaihatu, T. S. 2007. Kepemimpinan Transformasional dan Pengaruhnya Terhadap Kepuasan atas Kualitas Kehidupan Kerja, Komitmen Organisasi, dan Perilaku Ekstra Peran: Studi pada Guru-Guru SMU di Kota Surabaya. Jurnal Manajemen dan Kewirausahaan, VOL.98, NO. 1, Hal : 49-61.

Kreitner, Robert \& Angelo Kinicki. 2005. Perilaku Organisasi. Terjemahan:

Erly Suandy. Buku

1. Ed.5. Salemba Empat. Jakarta. 
Leephaijaroen Siripapun. 2016. Effects of the big-five personality traits and organizational commitments on organizational citizenship behavior ofsupport staff at UbonRatchathani Rajabhat University, Thailand. Kasetsart Journal of Social Sciences 37 $104 \mathrm{e} 111$.

Lian Lee Kim dan Tui Low Guan. 2012. Leadership Styles and Organizational Citizenship Behavior: The Mediating Effect of Subordinates' Competence and Downward Influence Tactics.Journal of Applied Business and Economics vol. 13(2).

Luthans, Fred. 2006.Perilaku Organisasi. Yogyakarta: Andi (alih bahasa Vivi Andhika Yuwono). Mathis, Robert L. dan John H. Jackson. (2010). Manajemen Sumber Daya Manusia, Edisi Pertama Salemba Empat, Jakarta.

Modassir, Atika \& Singh, Tripti. (2007). Relationshipof Emotional Inteelegence with Transformational Leadership add Organizational Citizenship Behavior. InternationalJournal of Leadership Studies(IJLS), Vol. 4(1), 3-21.

Moghimi dan Firozabad, 2013, The Mediating Effects of Psychological Empowerment and Job Satisfaction in the Relationship between Transformational Leadership and Organizational Citizenship Behavior, Journal of Basic and Applied, Vol. 3,No. 5.

Morgeson, F. P., and Humphrey, S. E. 2006. The Work Design Questionnaire (WDQ): Developing and Validating a Comprehensive Measure for Assessing Job Design and the Nature of Work,. Journal of Applied Psychology, Vol. 91, pp. 1321-1339.

Mowday,R.T.,R.M. Steers, dan L.W. Porter (2006), "The Measurument of Organizational Commitment", Journal of Vocational Behavior, Vol. 14 (April), pp. 224-47.

N.N.N. Dlamini., Professor Ajay K Garg., Professor M. Muchie Tshwane University of Technology Business School South Africa., 2017, The impact of transformational leadership style on organisational commitment in the hospitality industry, African Journal of Hospitality, Tourism and Leisure, Volume 6 (3) (2017) ISSN: 2223-814X.

Northouse, Peter G.2010.Kepemimpinan.Jakarta: PT Indeks.

Organ, D.W. and Ryan, K. (1995), "A meta-analytic review of attitudinal and dispositional predictors of organizational citizenship", Personnel Psychology, Vol. 48 No. 4, pp. 775-802.

Podsakoff, M., Scott, B.M., Paine, J.B., Bachrach, D.G. (1977). Organizational Citizenship Behavior: Acritical Reviewof The Theoritical And Empirical Literature And Suggsestion For Future Research. Journal Of Management. 26/3. p.513-563.

Pohl, Sabineet al. 2013. "The Impact of Perceived Organizational Support and Job Characteristics on Nurses Organizational Citizenship Behaviours", International Journal of Organization theory and Behavior, Volume 16, Nomor 2.

Priyatno, Duwi, 2011, Buku Saku Analisis Statistik Data SPSS, Mediakom, Yogyakarta.

Putra, gede Agus Eka \& Subudi, Made. 2017. Pengaruh Gaya Kepemimpinan 
Transformasional dan Budaya Organisasi terhadap Motivasi dalam meningkatkan Organizational Citizenship Behavior (OCB). E-Jurnal Manajemen Unud.Vol.6, No.4, hal:2047-2075.

Restin Meilina. 2016. Pengaruh Karakteristik Pekerjaan, Kepuasan Kerja Dan Komitmen Organisasi Terhadap OCB Pada Karyawan BRI Kediri, Vol XI, No.1.

Rivai, Veithzal. 2008. Manajemen Sumber Daya Manusia Untuk Perusahaan, Dari Teori ke Praktek. Jakarta: PT. Raja Grafindo Persada.

Robert,Anton Sabella\& Farhad Analoui. (2015). Managerial training anddevelopment in telecommunicationorganizations in Palestine. Journal of Management Development,34 (6), 685703.

Robbins, S. \& Judge, T. 2002.OrganizationalBehavior, 12th edition. New York: Prentice Hall. Robbins, S.P., Langton, N. (2007). Organizational Behavior. Concepts, Controversies, Applications. 4th Ed. New York : Prentice Hall.

Robbins SP, dan Judge. 2015. Perilaku Organisasiedisi 16, Jakarta: Salemba Empat.

Safari, Ali, Golshahi, Behanm, 2013, the effect of emotional intelligence of managers on organizational entrepreneurship, sixth edition, no.3, p.p 183-202.

Saybani H. , 2013, Ansthletes'Satisfaction as Mediator of Transformational Leadearship Behaviors Coaches and Foodball Players'Sport Commitment Relationship, World Applied Science Journal, Vol.21, No. 10.

Simamora, Henry, 2004, Manajemen Sumber Daya Manusia, Edisi Ketiga, Cetakan Pertama, Bagian Penerbitan STIE YKPN, Yogyakarta.

Steers, R.M. (1977). Antecedents and outcomes of organizational commitment. Administrative Science Quarterly, 22, 46-56.

Subudi, Made Dan Putra Gede Agus Eka. 2017.Pengaruh Gaya Kepemimpinan Transformasional Dan Budaya Organisasi Terhadap Motivasi Dalam Meningkatkan Organizational Citizenship Behavior, E-Jurnal Manajemen Unud,Vol. 6, No. 4, : 2047-2075 ISSN : 2302-8912, Fakultas Ekonomi Dan Bisnis Universitas Udayana, Bali, Indonesia.

Sugiyono. (2012). Memahami Penelitian Kualitatif". Bandung : ALFABETA. Sunyoto, Suyanto 2011. Analisis regresi untuk uji hipotesis, Yogyakarta.

Suryanata, S., Unny, C., \& Ramkumar, T. 2016. A Study on the Impact of Quality of Work Life on Organizational Citizenship Behavior among School Teachers. International Journal for Management Science And Technology (IJMST). 3(5):1-10.

Titisari, Purnamie. 2014. Peranan Organizational Citizenship Behaviour (OCB) dalam Meningkatkan Kinerja Karyawan. Jakarta: Mitra Wacana Media.

Utomo, K.W. 2002. kecenderungan kepemimpinan transaksional dan transformasional, dan hubungannya dengan organizational citizen-ship behavior, komitmen organisasi, dan kepuasan kerja. Journal Riset Ekonomi dan Manajemen. Surabaya. Vol. 2. 
PENGARUH GAYA KEPEMIMPINAN TRANSFORMASIONAL DAN KARAKTERISTIK PEKERJAAN

TERHADAP ORGANIZATIONAL CITIZENSHIP BEHAVIOR (OCB) DENGAN KOMITMEN ORGANISASIONAL SEBAGAI VARIABEL INTERVENING

(Studi pada PT Indonesia Comnets Plus Regional Kalimantan) Utin Devika Azzahroh a

No. 2. hal. 34-52.

Vandenberg, R.J., \& Lance, C.E. 1992. Examining the Causal Order of Job Satisfaction and Organizational Commitment. Journal of Management. 18: 153-167.

Yu Bo, 2013, The Influence Study of Transformational Leadership in University on Teachers'Organizational Commitment: The Construction and Verification of a Theoretical Model, Canadian social Study, Vol.9, No. 4.

Yukl, Gary. 2010. Leadership in Organizations. Prentice Hall. Inc. New Jersey.

Zurnali, Cut. 2010. Learning Organization, Competency, Organizational Commitment, And Customer Orientation: Knowledge WorkerKerangka Riset Manajemen Sumber Daya Manusia Masa Depan. Bandung: Unpad Press. 